\title{
Neoachryson, novo gênero de Achrysonini (Coleoptera, Cerambycidae, Cerambycinae)
}

\author{
Marcela L. Monné1,3 \& Miguel A. Monné2,4 \\ 1. Museu de Zoologia, Universidade de São Paulo, Caixa Postal 42494, 04218-970 São Paulo, SP, Brasil \\ 2. Museu Nacional, Universidade Federal do Rio de Janeiro, Quinta da Boa Vista, São Cristovão, 20940-040 Rio de Janeiro, RJ, \\ Brasil. \\ 3. Bolsista FAPESP \\ 4. Pesquisador CNPq
}

\begin{abstract}
Neoachryson, new genus of Achrysonini (Coleoptera, Cerambycidae, Cerambycinae). The new genus Neoachryson and its type-species, N. castaneum sp. nov., are described from Argentina (Mendoza).
\end{abstract}

KEYWORDS. Achrysonini, new genus, new species, taxonomy, Neotropical.

\section{INTRODUÇÃO}

A tribo Achrysonini Lacordaire, 1869 foi revista por MARTins (2002) que assinalou oito gêneros para a América do Sul e a distinguiu das demais tribos de Cerambycinae com olhos grosseiramente facetados, principalmente, pela presença de pêlos entre os omatídios. Acrescentamos novo gênero e nova espécie de Mendoza, Argentina. O material examinado pertence ao Museu Nacional, Universidade Federal do Rio de Janeiro, Rio de Janeiro (MNRJ).

A chave para os gêneros sul-americanos de Achrysonini apresentada por MarTins (2002:46) é adaptada para incluir Neoachryson gen. nov.

2(1). Pronoto com dois tubérculos no nível do terço anterior; élitros com elevação longitudinal mais evidente junto à base, prolongada até o quarto apical, delimita uma área aplanada para o lado da sutura ......... Abyarachryson Martins, 2002

Pronoto sem tubérculos (exceto pequenas gibosidades em algumas espécies de Achryson); élitros convexos ou aplanados nos $2 / 3$ apicais

\section{3a}

3a(2). Élitros aplanados nos 2/3 apicais; metafêmures lineares Neoachryson gen. nov.

Élitros uniformemente convexos; metafêmures de outra forma 3

Neoachryson gen. nov.

Espécie-tipo, Neoachryson castaneum sp. nov.

Fronte plana e vertical. Sutura coronal indicada até o nível dos lobos oculares superiores. Tubérculos anteníferos pouco projetados, moderadamente próximos entre si. Olhos desenvolvidos, não estreitados entre os lobos e com pêlos diminutos entre os omatídios. Lobos oculares superiores com quatro fileiras de omatídios e tão distantes entre si quanto, pelo menos, o dobro da largura de um lobo. Lobos oculares inferiores com aspecto arredondado, ocupam quase todo o lado da cabeça e não atingem a face ventral. Genas curtas, subtriangulares, com ápices aguçados e cerca de 1/4 do diâmetro do lobo ocular inferior. Mandíbulas arredondadas na margem externa. Antenas com 11 antenômeros, alcançam o terço apical dos élitros. Escapo subcilíndrico, ligeiramente curvo e tão longo quanto o antenômero III; III cerca de $1 / 3$ mais longo que $o$ IV; V-IX subiguais em comprimento; $\mathrm{X}$-XI subiguais e cerca de $1 / 3$ mais curtos que o IX.

Protórax quase tão largo quanto longo, com lados subarredondados. Pronoto plano. Cavidades coxais anteriores arredondadas, não-angulosas lateralmente. Processo prosternal estreito, sem superfícies articulares laterais. Mesosterno subplano. Processo mesosternal cerca da metade do diâmetro de uma mesocoxa, entalhado na extremidade e sem projeções laterais. Metasterno, na região mediana, plano. Sulco metasternal apenas alcança o terço basal. Escutelo pequeno, transverso e com a margem apical arredondada.

Élitros cerca de quatro vezes o comprimento do protórax, aplanados nos 2/3 apicais e com ápices arredondados e inermes. Úmeros arredondados e ligeiramente projetados.

Pernas posteriores $1 / 3$ mais longas que as anteriores. Procoxas arredondadas e salientes. Mesocoxas ovaladas. Fêmures subcilíndricos. Tíbias cilíndricas, tão longas quanto os fêmures. Metatarsômero I tão longo quanto II+III. Escovas tarsais com faixa glabra mediana longitudinal.

Urosternito I com comprimento subigual ao seguinte. Urosternito V com a margem apical arredondada.

Discussão. Entre os gêneros sul-americanos de Achrysonini, assemelha-se a Achryson Audinet-Serville, 1833, Cotyachryson Martins, 2002 e Xenocompsa Martins, 1965 por apresentar os antenômeros basais cilíndricos, antenômero IV mais curto que o III, lados do protórax inermes e pronoto sem tubérculos. Neoachryson difere destes gêneros, além dos caracteres mencionados na chave, pelos lobos oculares superiores com quatro fileiras de omatídios e pelas escovas tarsais com faixa glabra mediana longitudinal. Achryson, Cotyachryson e 


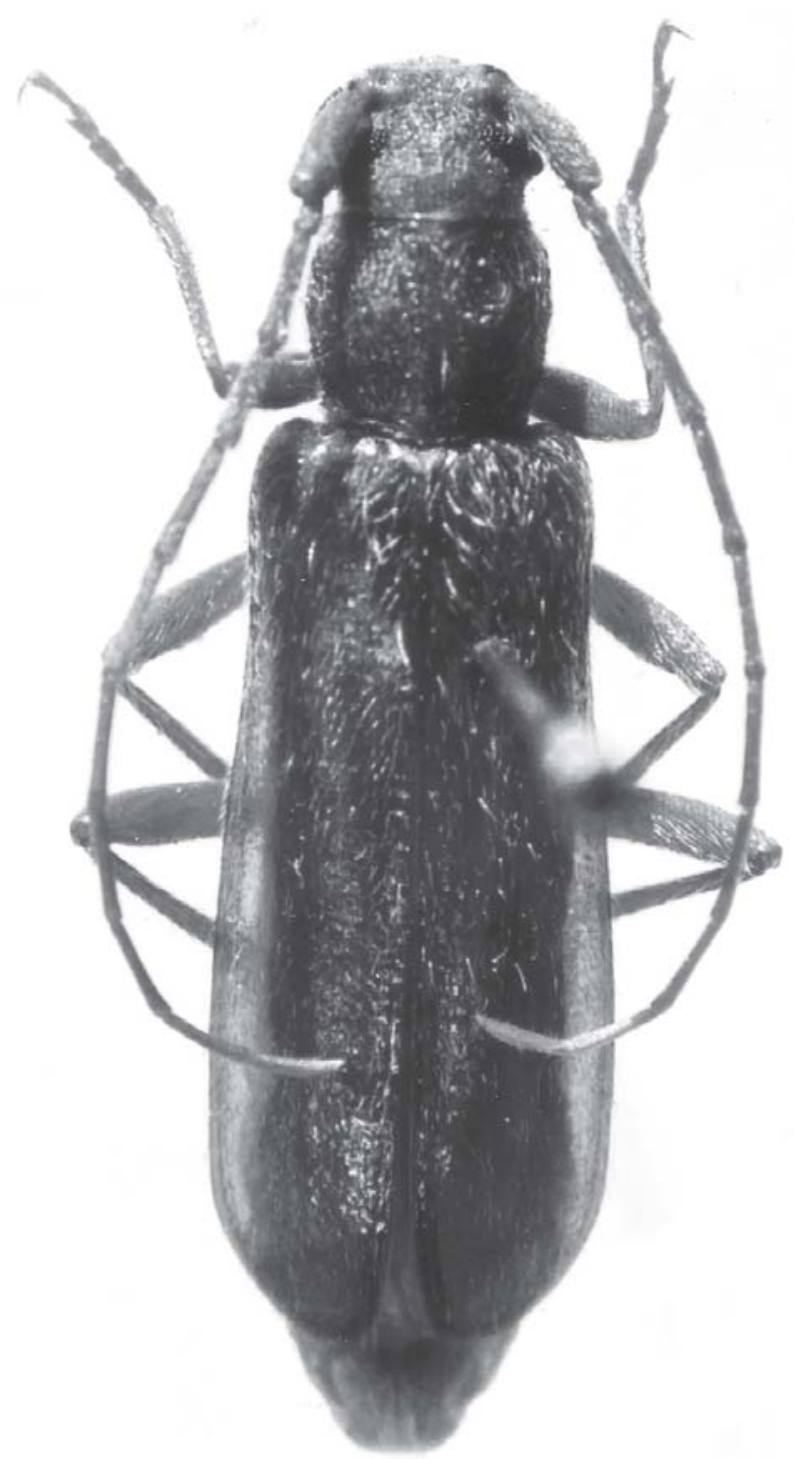

Fig. 1. Neoachryson castaneum sp. nov., holótipo †, Argentina (Mendoza), comprimento 11,9 mm.

Xenocompsa apresentam, respectivamente, 6-10, 5 e 3 fileiras de omatídios nos lobos oculares superiores, exceto $X$. flavonitida (Fairmaire \& Germain, 1859), e escovas tarsais compactas, sem faixa glabra.

\section{Neoachryson castaneum sp. nov. (Fig. 1)}

†. Colorido geral castanho-avermelhado. Face ventral do corpo revestida por pilosidade curta, esbranquiçada, moderadamente densa. Cabeça, antenas e pronoto com pontos finos, rasos e densos e pêlos curtos, densos e esbranquiçados. Prosterno com pontos finos, rasos e confluentes. Élitros (fig. 1) com pontos maiores que os do pronoto, rasos e moderadamente densos; pilosidade amarelada decumbente, moderadamente densa, entremeada por pêlos mais longos, eretos, esparsos e duas faixas glabras longitudinais. Fêmures e tíbias com pontos finos e granulados e pilosidade densa e esbranquiçada.

Dimensões, em mm, ๆ. Comprimento total, 11,9; comprimento do protórax, 2,0; maior largura do protórax, 2,3; comprimento do élitro, 8,6; largura umeral, 3,1.

Material-tipo. ARGEnTINA, Mendoza: Tupungato (Pampa de cebo), holótipo $\subsetneq$, I.1940, Koehler col. (MNRJ).

Agradecimentos. À FAPESP pela concessão da bolsa de estudo (Proc. 03/00511-3).

\section{REFERÊNCIA BIBLIOGRÁFICA}

Martins, U. R. 2002. Tribo Achrysonini. In: Martins, U. R. org. Cerambycidae sul-americanos (Coleoptera). Taxonomia. São Paulo, Sociedade Brasileira de Entomologia. v. 4, p.37144. 